\title{
INTERPRETATION OF WELL LOGS IN A CARBONATE AQUIFER
}

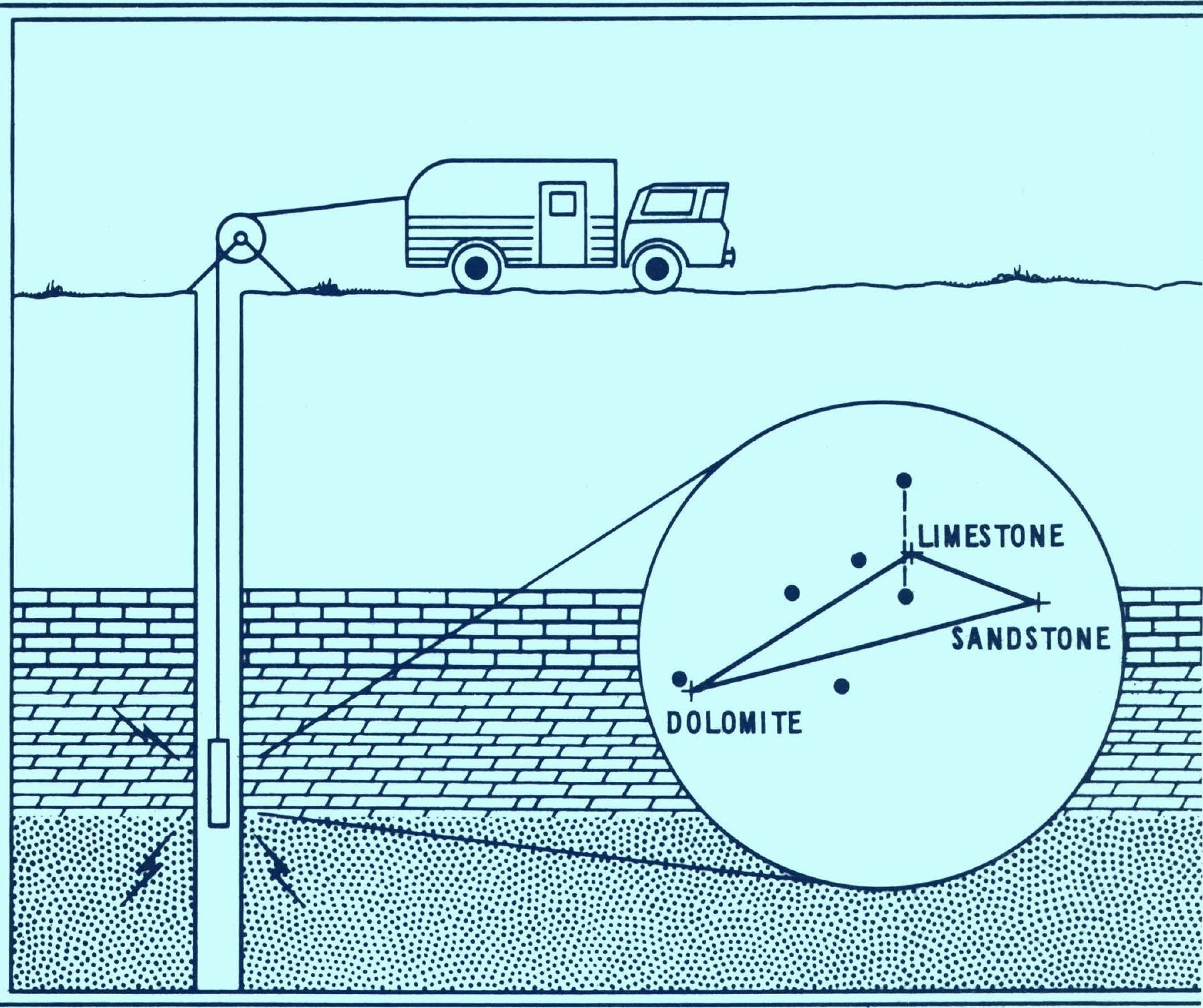

U.S. GEOLOGICAL SURVEY

Water-Resources Investigations $78-88$

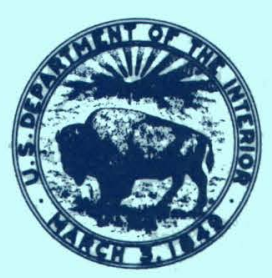




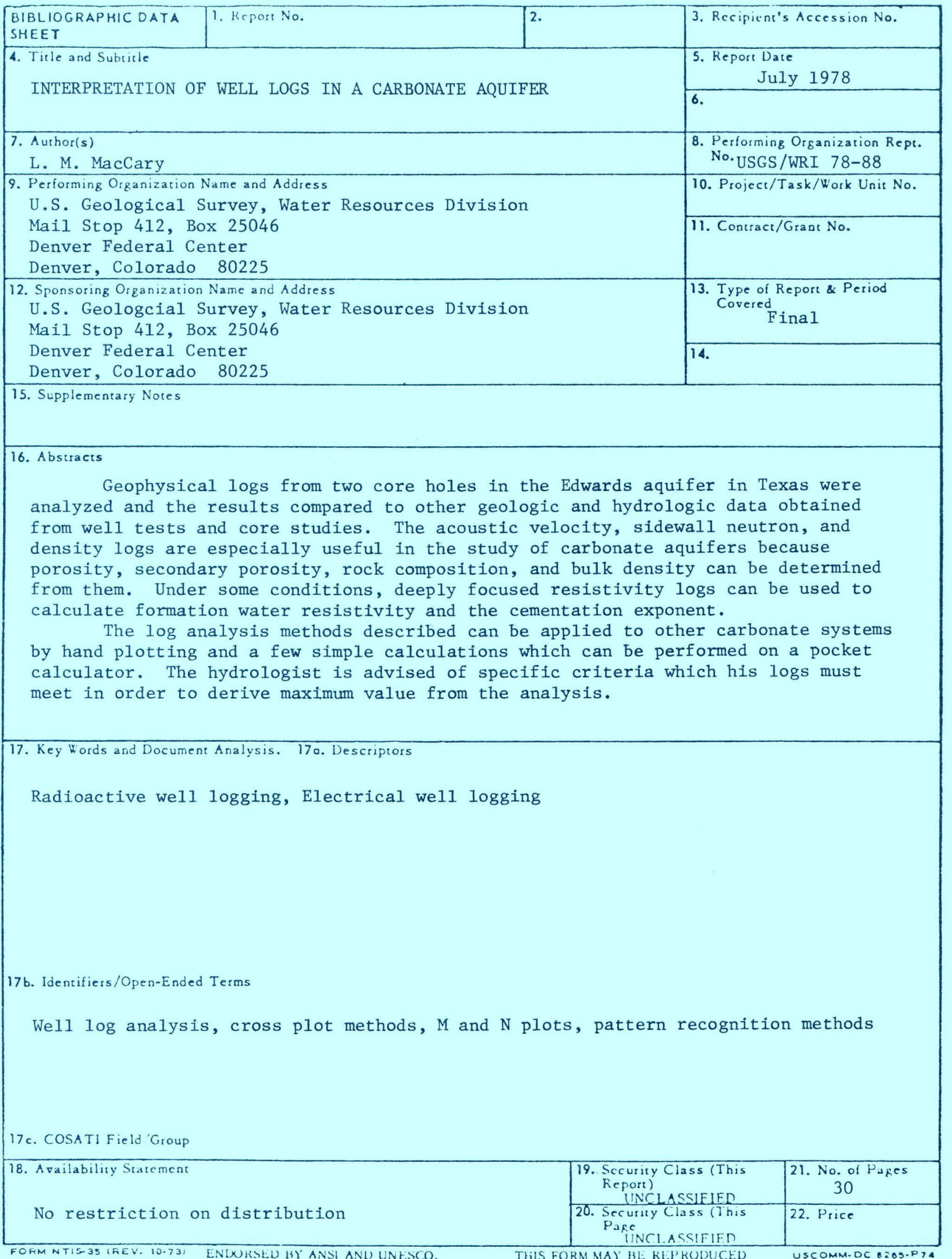


INTERPRETATION OF WELL LOGS IN A CARBONATE AQUIFER

By L. M. MacCary

U.S. GEOLOGICAL SURVEY

Water-Resources Investigations 78-88

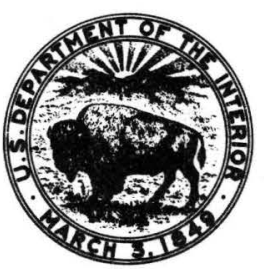

July 1978




UNITED STATES DEPARTMENT OF THE INTERIOR

CECIL D. ANDRUS, Secretary

GEOLOGICAL SURVEY

H. William Menard, Director

For additional information write to:

U.S. Geological Survey

Water Resources Division

Mail Stop 412, Box 25046

Denver Federal Center

Denver, Colorado 80225 
Metric conversion table

Introduction

Response of logging systems in carbonate aquifers--

Principles of quantitative log analysis--

Practical carbonate rock analysis--

Porosity and water quality determinations-_-_-

Significant results of quantitative $10 \mathrm{~g}$ analysis-_-_-_-_-_---_----

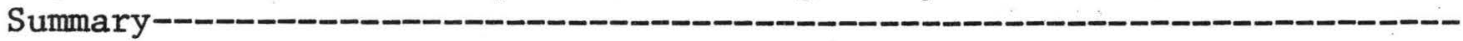

References-- - - - -

\section{ILLUSTRATIONS}

Figure 1. Map showing location of study area--_-_-_-_-_-_-_-- 3

2. Idealized logs and plot of two mineral components--_-_- 6

3. Idealized plot of three-mineral-component system--_-_--- 7

4. Geophysical logs of the Randolph core hole--_-_-_-_-_-- 10, 11

5. Neutron-density plot of 13 zones from Randolph core hole-- 12

6. M-N plot of 13 zones from Randolph core hole-_-_-_-_- 15

7. Sonic-neutron plot of 13 zones from Randolph core hole---_- 16

8. Porosity-resistivity plot of 13 zones from Randolph core hole-- 19

9. Geophysical logs of the Sabinal core hole--_- 22, 23

10. Neutron-density plot of seven zones from Sabinal core hole--_- 24

11. M-N plot of seven zones from Sabinal core hole--_-_-_--- 26

12. Sonic-neutron plot of seven zones from

Sabinal core hole--_ 27

\section{TABLES}

Table 1. Geophysical log data from Randolph core hole------------- 8

2. Computed values of $\mathrm{M}$ and $\mathrm{N}$ for Randolph core hole-------- 14

3. Geophysical log data from Sabinal core hole----- 21

4. Computed values of $\mathrm{M}$ and $\mathrm{N}$ for Sabinal core hole-------- 25 
English units in this report may be converted to metric units by using the following conversion factors:

Multiply English units

inches (in)

inches

feet ( $f t)$

feet
By

25.4

2.54

0.3048

30.48
To find metric units millimeters (mm)

centimeters (cm)

meters (m)

centimeters 


\title{
INTERPRETATION OF WELL LOGS
}

IN A CARBONATE AQUIFER

By L. M. MacCary

\begin{abstract}
This report describes the log analysis of the Randolph and Sabinal core holes in the Edwards aquifer in Texas, with particular attention to the principles that can be applied generally to any carbonate system. The geologic and hydrologic data were obtained during the drilling of the two holes, from extensive laboratory analysis of the cores, and from numerous geophysical logs run in the two holes.

Some logging methods are inherently superior to others for the analysis of limestone and dolomite aquifers. Three such systems are the density, neutron, and acoustic-velocity (sonic) logs. Most of the log analysis described here is based on the interpretation of suites of logs from these three systems. In certain instances, deeply focused resistivity logs can be used to good advantage in carbonate rock studies; this technique is used to compute the water resistivity in the Randolph core hole.

The rocks penetrated by the Randolph core hole are typical of those carbonates that have undergone very little solution by recent ground-water circulation. There are few large solutional openings; the water is saline; and the rocks are dark, dolomitic, have pore space that is interparticle or intercrystalline, and contain unoxidized organic material. The total porosity of rocks in the saline zone is higher than that of rocks in the freshwater aquifer; however, the intrinsic permeability is much less in the saline zone because there are fewer large solutional openings.

The Sabinal core hole penetrates a carbonate environment that has experienced much solution by ground water during recent geologic time. The rocks have high secondary porosities controlled by sedimentary structures within the rock; the water is fresh; and the dominant rock composition is limestone.

The relative percentages of limestone and dolomite, the average matrix (grain) densities of the rock mixtures, and the porosity of the rock mass can be calculated from density, neutron, and acoustic logs. With supporting data from resistivity logs, the formation water quality can be estimated, as wel1 as the relative cementation or tortuosity of the rock. Many of these properties calculated from logs can be verified by analysis of the core available from test holes drilled in the saline and fresh water zones.
\end{abstract}




\section{INTRODUCTION}

Hydrologists recognize fundamental differences between carbonate and clastic aquifers, especially the differences in porosities, permeabilities, chemistry, and aquifer tests. Fluid flow, for example, is vastly different in a fractured, vuggy limestone than in a homogeneous sand formation. These very differences, that challenge the ground-water scientist, are sometimes an enigma to the $\log$ analyst studying geophysical logs of carbonate rocks.

Ground-water students increasingly rely on well logs as a source of data for geologic correlation, well-performance evaluation, aquifer porosity, lithology, and water quality. Many of the techniques used in petroleum log analysis can be applied directly to ground-water studies in clastic rocks with good results. When the logging techniques and analysis methods developed for sand-shale environments are uncritically applied to limestone-dolomite systems, the product may be disappointing. This fact was recognized early by petroleum researchers who spearheaded the development of logging systems and analysis techniques that were tailored especially for carbonate reservoirs.

Much has been written on the classification of carbonate rocks, their pore geometry, and fluid flow. A good discussion of carbonate oil reservoir rocks is presented in Chillingar and others (1972), and their analysis of pore geometry and fluid flow will be of interest to those working in hydrology. A recent open-file report by Maclay and Small (1976) details their classification of carbonate rocks in the ground-water environment and contains an analysis of the mercury injection tests they used to determine pore geometry. Figure 1 shows the location of the Randolph and Sabinal core holes, and the bad water line discussed in this report.

It is not the intent of this report to present an exhaustive analysis of limestone and dolomite aquifers. The main objective is to discuss some of the logging techniques of proven value in carbonate rocks, and some of the methods of $\log$ analysis that yield quantitative data.

\section{RESPONSE OF LOGGING SYSTEMS IN CARBONATE AQUIFERS}

Limestone or dolomite aquifers often are the fractured or porous zones within a body of massive, low-porosity carbonate rock. In a typical fresh water system, the apparent resistivities recorded in the dense rock may be hundreds or even thousands of ohm-meters. The high porosity zones, because of the greater amounts of water they contain, are recorded as resistivity lows that depart from an otherwise high resistivity base line.

Conventional electric logs (normals, lateral, and spontaneous potential or SP) depend on the electrical conductivity of the borehole fluid to couple the logging electrodes to the formations being surveyed. Even though the borehole fluid may be fresh in a well drilled in carbonates, the fluid is so much more conductive than the low-porosity rock, that most of the current moves along the borehole. Since most of the resistivity signal originates in the borehole, the logs lack character and are difficult to analyze for quantitative data. 


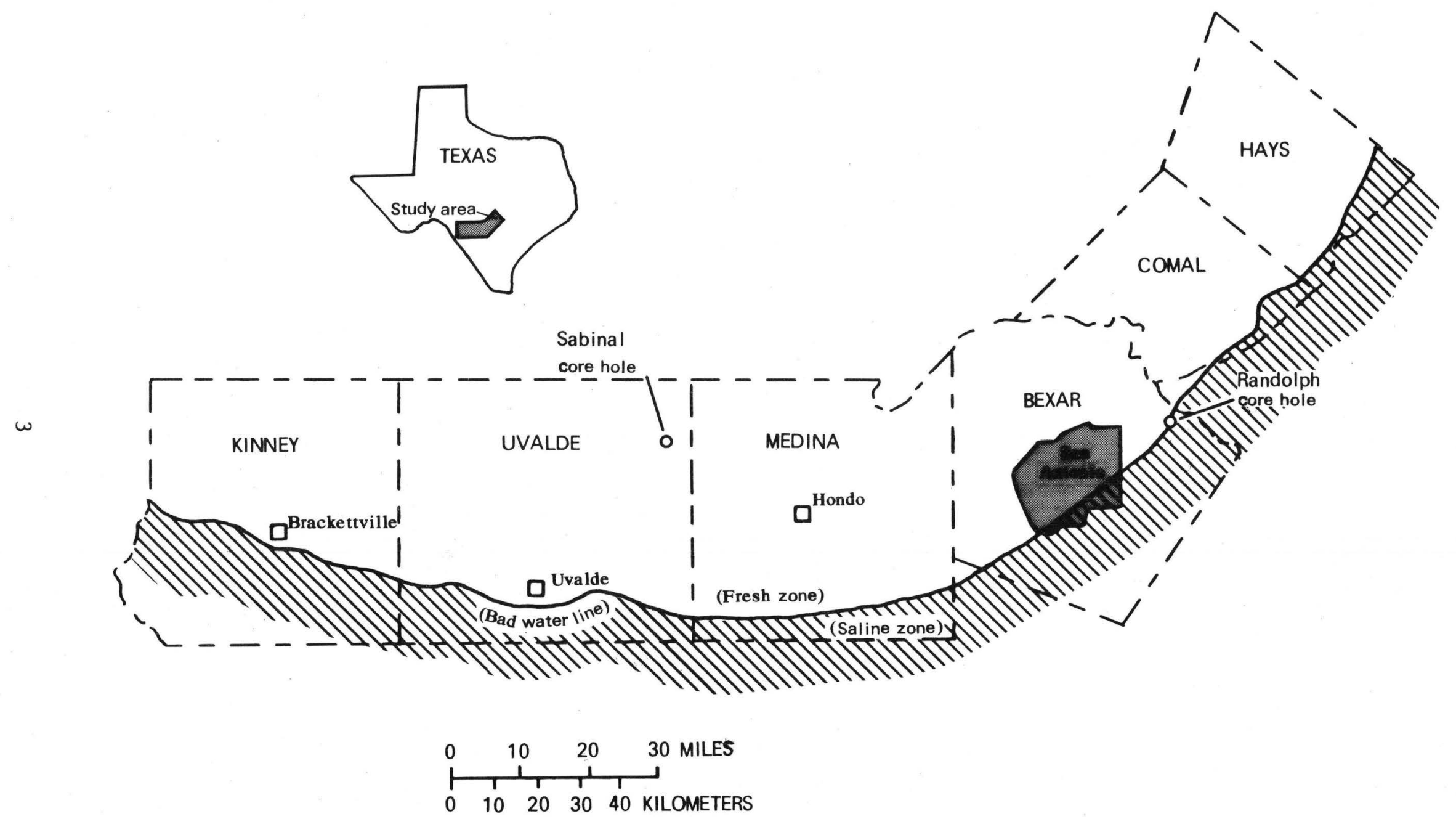

Figure 1.--Location of study area. 
Induction logs have their greatest resolution where the resisitivity is less than about $100 \mathrm{ohm-meters.} \mathrm{In} \mathrm{the} \mathrm{highly} \mathrm{resistive} \mathrm{environment} \mathrm{pre-}$ sented by carbonate rocks saturated with fresh water, the induction curve appears compressed at the right side of the log sheet beginning at about 1,400 ohm-meters, and frequently will be flat-topped on the 2,000-ohm-meter scale mark. The only places where the curve falls to a low resistivity are in the zones of greatest porosity. The SP tends to lack definition in dense, resistive carbonates, and it would be difficult to pick bed boundaries from this curve (Schlumberger Well Surveying Corp., 1958).

Dolomites generally have a higher intercrystalline or sucrosic porosity than that found in dense limestones. Some dolomites therefore appear to act like cemented clastic rocks on the resistivity curves (MacCary, 1971). When carbonates have a uniformly distributed intergranular porosity, the electric logs can be used to calculate formation water quality and even porosity. When most of the porosity resides in fractures, solution openings, and bedding plane voids, the electric logging current seeks out these conductive paths and the resistivities recorded are not representative of the mass of rock.

The deeply-focused resistivity logs (laterolog or guard) may be superior to conventional and induction systems for logging in carbonate rocks. Laterologs of the LL3, LL7, and LLd types are the most useful, because they survey a thin slice of rock 12 to 32 inches thick, are strongly focused to eliminate borehole and adjacent-bed effects and thus derive most of the resistivity signal from beyond the invaded zone (Schlumberger Limited, 1969). In extremely low porosity rocks they too tend to peak at some high resistivity reading that is beyond the resolving power of the system.

The acoustic or sonic system records the time of travel of an acoutic pulse through a fixed length of rock parallel to the borehole. The mineral components of sedimentary rocks have well-established matrix (or grain) interval transit times $(\Delta t)$ that range from about 42 microseconds per foot $(\mu \mathrm{s} / \mathrm{ft}$ ) for a dolomite of zero porosity to $67 \mu \mathrm{s} / \mathrm{ft}$ for a nonporous sandstone (Schlumberger Limited, 1969). Uncompacted shales may be as slow as $167 \mu \mathrm{s} / \mathrm{ft}$, and highly compacted shales as fast as $63 \mu \mathrm{s} / \mathrm{ft}$. As the intergranular porosity increases, the time of travel for the acoustic pulse grows longer; thus, a dolomite of 35-percent porosity will have an interval transit time of about $95 \mu \mathrm{s} / \mathrm{ft}$. It is apparent that the acoustic $\log$ is sensitive to both the rock matrix type and the porosity.

The density (gamma-gamma) log records the attenuation of a scattered beam of gamma radiation that is focused into the rocks along the borehole wall. The amount of attenuation is proportional to the density of the rock matrix penetrated and inversely proportional to the porosity. The matrix densities of common rocks range from $2.65 \mathrm{~g} / \mathrm{cm}^{3}$ (grams per cubic centimeter) for zero porosity quartz sandstone, to $2.87 \mathrm{~g} / \mathrm{cm}^{3}$ for nonporous dolomite. As porosity increases, the bulk density goes down; therefore, a dolomite of 35-percent porosity will have a bulk density of about $2.27 \mathrm{~g} / \mathrm{cm}^{3}$. The term "bulk density" is applied to the value measured by the $10 \mathrm{~g}$, because it includes both rock matrix and porosity effects. 
The neutron log records the degree of moderation of neutrons that enter the borehole wall and are detected by a highly collimated detector or detectors. In the typical sedimentary environment, the neutrons are moderated mainly by hydrogen; thus, the log is representative of the total water content of the rocks. This may include pore water between mineral grains, bound or adsorbed water in clay, or even water of crystallization in gypsum. There are also rock matrix effects in addition to the fluid effects on this log.

\section{PRINCIPLES OF QUANTITATIVE LOG ANALYSIS}

Quantitative log analysis is based on the ways different logging devices respond to the matrix and porosity of formations. In the simplest case, assume a borehole that penetrates two formations, one of which is pure mineral $X$ and the other is pure mineral $Y$, as depicted by Jeffries (1969). Further, assume two logging devices are run through this borehole as shown in figure 2. Log $A$ has a maximum response to mineral $X$ and a minimum to mineral $Y$. Log $B$ has the inverse response to the two minerals. If the responses are plotted on a graph as in figure 2, a linear relationship is apparent, with mineral $\mathrm{X}$ at one end of the plot and mineral $\mathrm{Y}$ at the other. The plot can be scaled off from 0 to 100 percent of mineral X (or $\mathrm{Y}$ ). In the example illustrated, the two minerals might be anhydrite and salt, and the logs might be the acoustic and density. In a two-component system like this, it would be easy to identify the mineral end points (pure X or Y), and also mixtures of the two, from logs $A$ and $B$, assuming neither mineral had any porosity. Add a third mineral, and the system becomes a bit more complex, and can now be represented by a triangle, with mineral $\mathrm{Z}$ lying at an apex. Mixtures of the three can still be identified from logs $A$ and $B$, as in figure 3. However, if we add a fourth mineral or a component such as porosity, the system becomes a tetrahedron, with an apex out of the plane of the original triangle, and a third logging system would be necessary to identify all members uniquely. For example, we might use the neutron log to analyze the porosity component of the salt and anhydrite minerals mentioned above.

\section{PRACTICAL CARBONATE ROCK ANALYSIS}

Practical log analysis of carbonate reservoirs makes particular use of the response of the sonic, density, and neutron logs by plotting them in various combinations of pairs on graphs (also called cross plots in logging 1iterature). Log analysis by cross plot is a matter of observing where data points fall in relation to known end points, and also of recognizing particular patterns on the graph.

There is a certain amount of error in each logging system, and when two such measurements are plotted on the graphical axes, a rectangular error band results. A further complication occurs when logs are improperly calibrated, erroneously scaled, drifting due to some malfunction, or recording improperly due to hole size effects, invasion, or other imponderables. It becomes the job of the log analyst to evaluate all these factors and make the best interpretation, based on his knowledge of the geology and hydrology. 

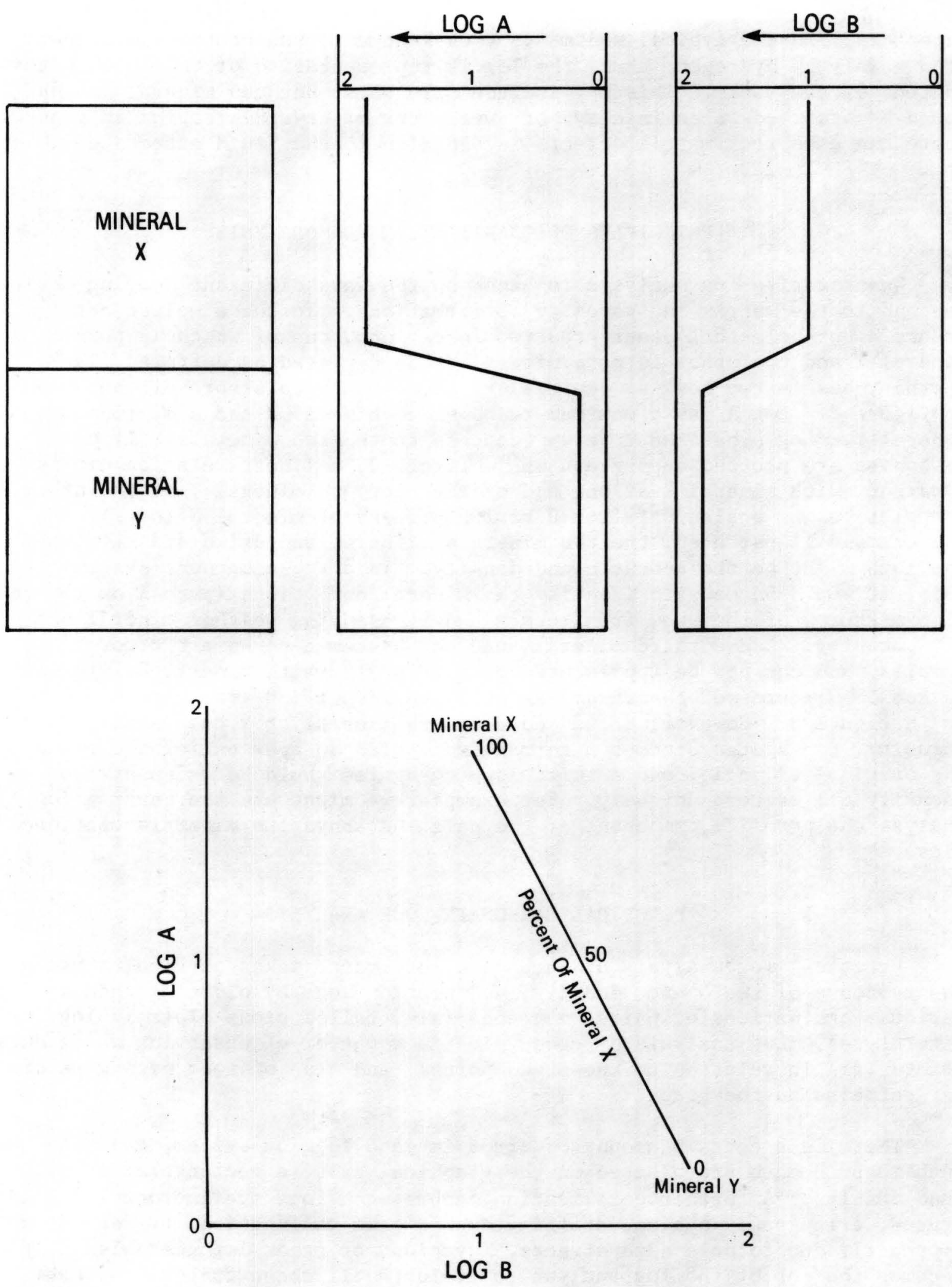

Figure 2.--Idealized logs and plot of two mineral components. 


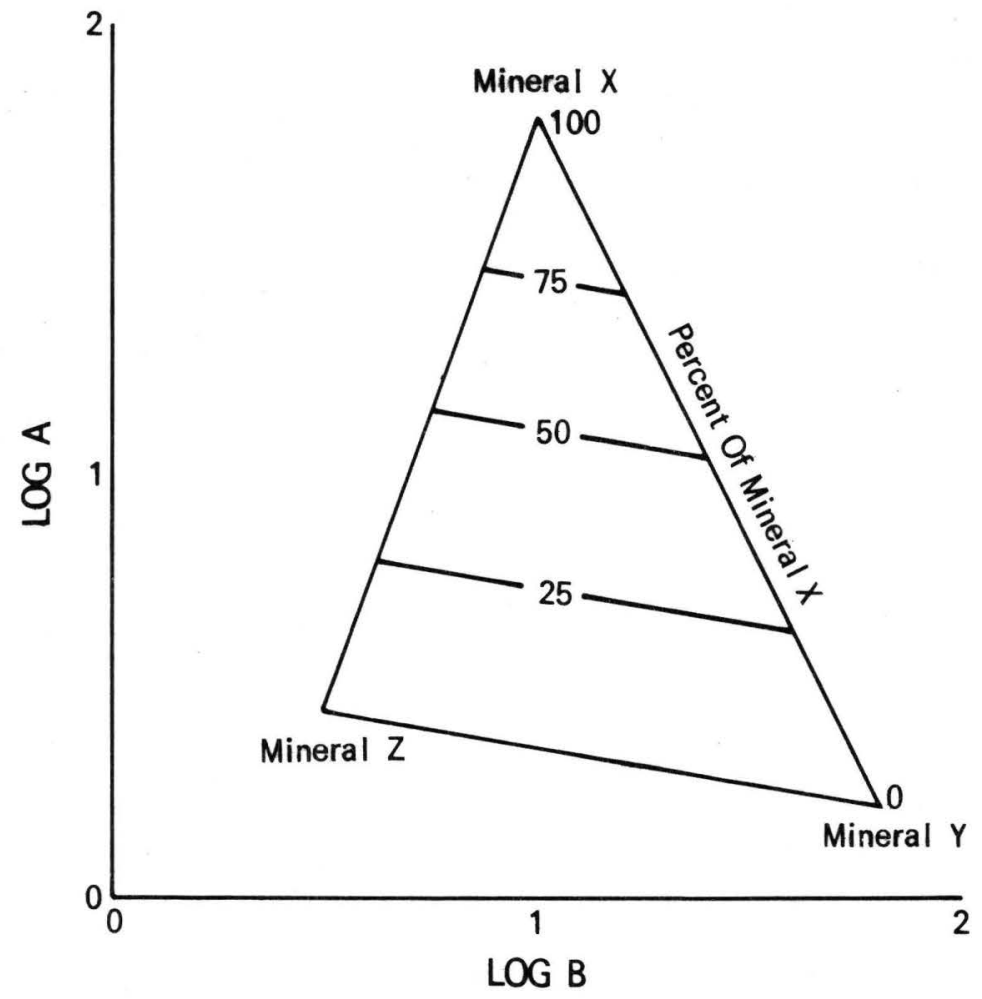

Figure 3.--Idealized plot of three-mineral-component system. 
Figure 4 shows the sonic, three-arm caliper, laterolog, sidewall neutron, and density logs of the Randolph core hole in the Edwards aquifer of Texas. The SP, caliper, and gamma ray appear in various combinations in the left track of some of the above-named logs. Study of the core indicates this well penetrated limestone, dolomite, and mixtures of the two. It is obvious that an inordinate amount of time would be required to make a quantitative analysis of the nearly 600 ft of carbonate rocks. A good understanding of the rock penetrated can be gained by selecting several zones for study. The sensitive three-arm caliper shows the hole size to lie between 6 and 9 in. with most of the hole being less than 8 in.diameter. Thirteen zones were chosen because they were either maximum deflections on the sonic, neutron, and density curves, minimum deflections on the three curves, or because all three curves tracked on some average value for several feet. Table 1 summarizes the values read from each $10 g$ for the depth range indicated, and also includes the resistivity from the laterolog. The hydrologist should avoid log transition areas for zone selection, because the logging sonde is leaving one environment and entering another. The slopes of these transition areas are influenced by logging speed, time constant, and the volume of investigation of the particular sonde, as well as lithology and porosity. It is best to take several readings and average them for the zone of interest. The methods described here are suitable for a pocket calculator. The values in table 1 are averages from $\frac{1}{2}-\mathrm{ft}$ intervals read from each curve.

Table 1.--Geophysical-log data from Randolph core hole

\begin{tabular}{|c|c|c|c|c|c|}
\hline Zone & $\begin{array}{l}\text { Depth } \\
\text { (ft) }\end{array}$ & $\begin{array}{c}\text { Average } \Delta t \\
\mu s / f t\end{array}$ & $\begin{array}{c}\text { Average } \\
{ }_{\text {SNP }} \\
\text { percent }\end{array}$ & $\begin{array}{l}\text { Average } \\
\rho_{b} \\
\mathrm{~g} / \mathrm{cm}^{3}\end{array}$ & $\begin{array}{c}\text { Average } \\
\mathrm{R}_{\text {LLD }} \\
\text { ohm-meters }\end{array}$ \\
\hline 1 & $634.0-635.5$ & 63.5 & 11.7 & 2.51 & 384.8 \\
\hline$\overline{2}$ & $671.5-\quad 673.0$ & 62.5 & 15.3 & 2.46 & 632.9 \\
\hline 3 & $755.5-\quad 758.0$ & 85.3 & 35.3 & 2.25 & 93.3 \\
\hline 4 & $798.5-801.0$ & 57.4 & 13.3 & 2.54 & 383.1 \\
\hline 5 & $802.0-805.0$ & 87.1 & 34.8 & 2.28 & 80.2 \\
\hline 6 & $848.5-\quad 851.5$ & 85.6 & 27.2 & 2.30 & 72.1 \\
\hline 7 & $983.5-\quad 986.0$ & 80.0 & 28.3 & 2.31 & 127.6 \\
\hline 8 & $1,004.5-1,010.0$ & 70.9 & 22.3 & 2.43 & 162.2 \\
\hline 9 & $1,015.0-1,020.0$ & 75.3 & 23.8 & 2.40 & 74.6 \\
\hline 10 & $1,037.5-1,039.5$ & 94.4 & 33.1 & 2.21 & 69.6 \\
\hline 11 & $1,055.5-1,057.5$ & 88.8 & 32.3 & 2.24 & 73.6 \\
\hline 12 & $1,068.5-1,072.0$ & 85.6 & 30.4 & 2.23 & 83.9 \\
\hline 13 & $1,156.0-1,157.5$ & 63.1 & 9.4 & 2.60 & 61.7 \\
\hline
\end{tabular}


Shale beds and zones of unusual hole enlargement should be avoided in the quantitative analysis for porosity and mineralogy. Shales can be identified from the cuttings; lacking these, the hydrologist can usually identify them by their large positive SP values and high natural gamma readings. Hole enlargements and washout areas can be spotted on the caliper log. Shales are indicated as unusually high porosity on the neutron curve, as are washouts. The latter also cause anomalies on both the density and sonic curves. No thick shales are evident from an examination of the SP and gamma ray of the Randolph core hole. Thin, wispy shales were logged in the core, and they may affect some log readings. The logs of the Randolph core hole are typical of those in a carbonate environment that has few solution openings. The hole is generally smooth with few secondary openings, and the core studies indicate the rock contains large percentages of dolomite. This hole lies on the "bad water" line which separates the fresh water to the north from saline water to the south (Maclay and Sma11, 1976).

Probably the most commonly used cross plots are those described by Raymer and Biggs (1963). They graphed neutron-density, sonic-density, and sonic-neutron combinations to analyze well logs for porosity and lithology. The neutron-density graph consists of three type-curves, each beginning at a zero porosity matrix point (quartz sandstone, limestone, and dolomite), and all ending at a common fluid point that represents 100 percent waterfilled porosity. This point lies far beyond the useful limits of the logging systems, and the graph usually ends at 40-percent porosity. Figure 5 is the neutron-density plot for the 13 zones listed in table 1 . All the data points fall either on or close to the limestone and dolomite matrix lines or lie between them. The matrix lines of figure 5 are scaled in porosity units from 0 percent at the pure mineral end points, to 35 percent on the dolomite line, and 40 percent on the limestone and sandstone lines. Because rock matrix has an effect on the neutron curve, which was calibrated in a limestone pit, a 10-percent reading would also indicate a dolomite of 7.5-percent porosity, or a sandstone of 13-percent porosity. In order to correct for rock mixtures, the corresponding porosity values on the matrix lines are joined by straight lines, and the porosity of each zone is interpolated. For example, the dashed lines between the 20 and 25-percent points on the limestone and dolomite lines are used to interpolate a 22-percent porosity for zone 9. Furthermore, because zone 9 lies between pure limestone at $2.71 \mathrm{~g} / \mathrm{cm}^{3}$ and pure dolomite at $2.87 \mathrm{~g} / \mathrm{cm}^{3}$, the matrix density of this zone can be interpolated by marking the 22-percent line into density units, one of which, the $2.79-\mathrm{g} / \mathrm{cm}^{3}$ density of a 50-50 mixture, is shown on the figure. The matrix density of zone 9 , therefore, is about $2.80 \mathrm{~g} / \mathrm{cm}^{3}$. We have thus derived two additional pieces of information: the actual rock porosity and the matrix density, from the bulk density and the apparent neutron porosity. Similarly, all the remaining zones can be examined to determine their porosities and matrix densities.

Zone 5 is anomalous because, by using the above method, it will have a matrix density somewhat in excess of $2.87 \mathrm{~g} / \mathrm{cm}^{3}$; however, core analysis indicates that dolomite is the most dense mineral observed in this part of the core hole. 


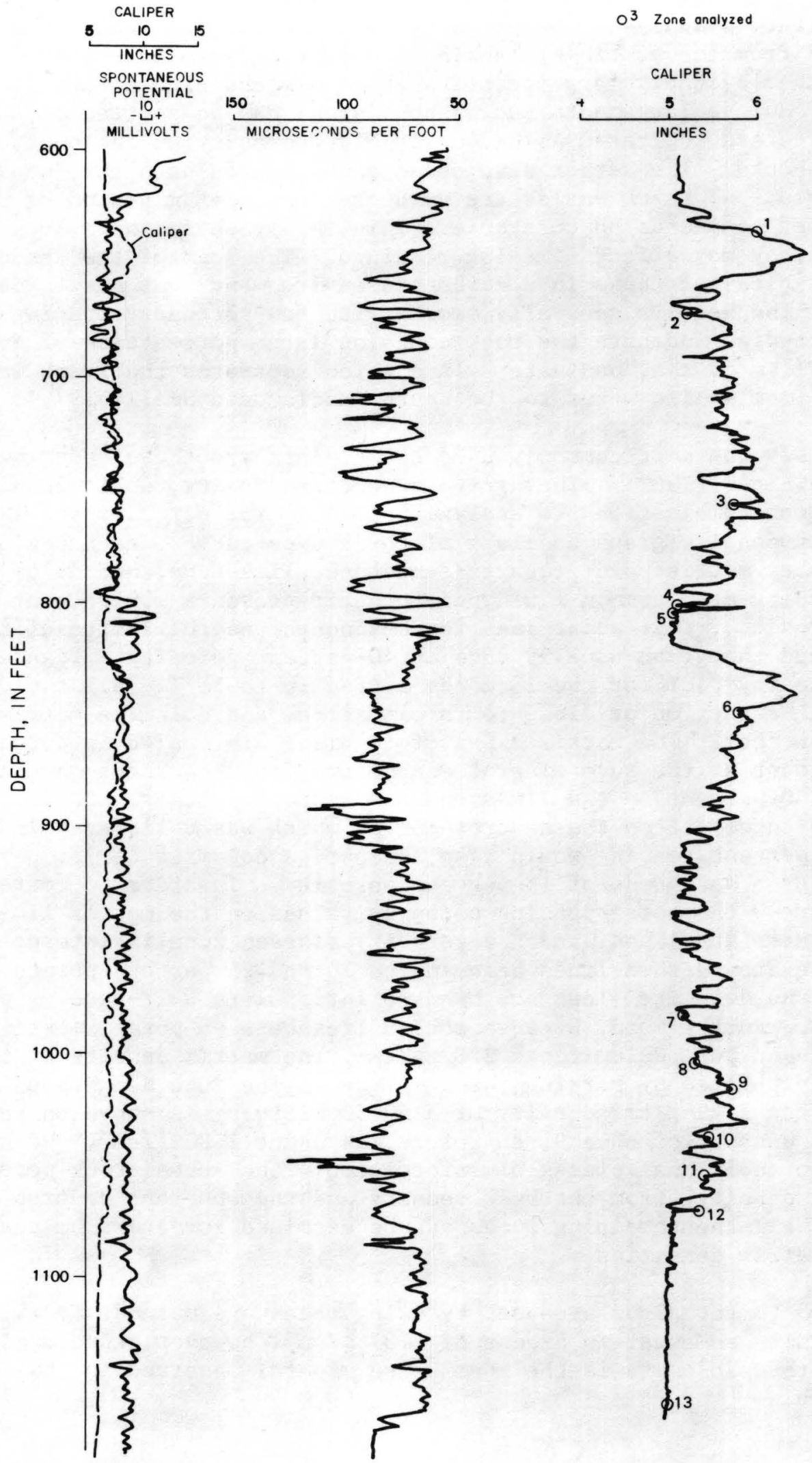

Figure 4.--Geophysical logs of the Randolph core hole. 


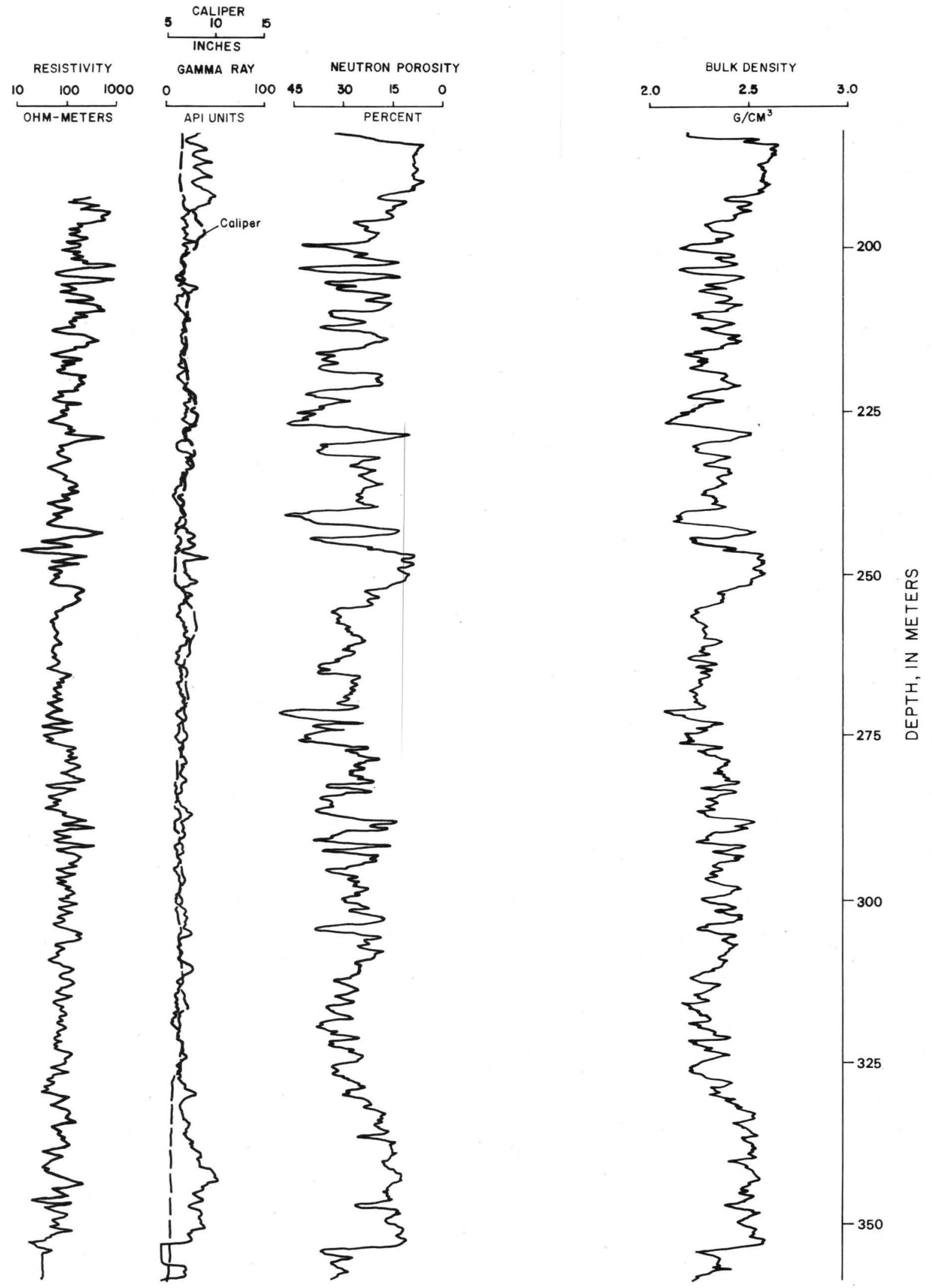

Figure 4.--Continued 


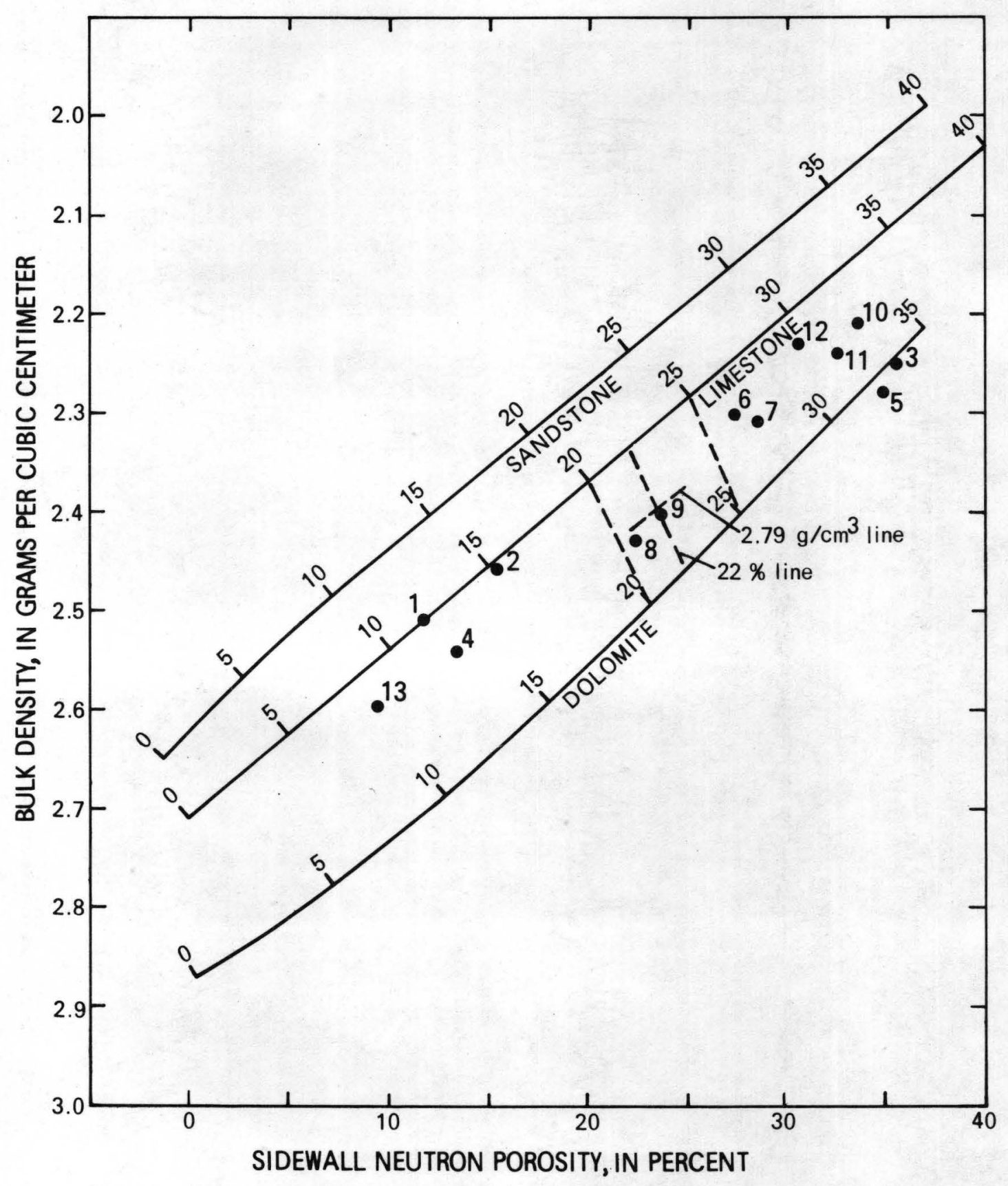

Figure 5.--Neutron-density plot of 13 zones from Randolph core hole. 
There are several reasons why zones might plot to the right of the dolomite line. One, of course, is that the zones actually do contain significant amounts of a mineral heavier than dolomite. Another is that the zones contain shale. Shales are extremely variable in their log response depending on the degree of compaction. Densities of shales range from less than $2.2 \mathrm{~g} / \mathrm{cm}^{3}$ to a maximum of about $2.65 \mathrm{~g} / \mathrm{cm}^{3}$ for highly compacted shales. As the density increases, the porosity decreases from more than 40 percent to less than 16 percent. Shales generally occupy the region to the right of the dolomite line due to their high apparent porosities on the neutron tool.

Most likely, zone 5 plots to the right of the dolomite-type curve because the neutron tool is reading too much porosity. In computer analyses, the usual approach is to subtract small amounts of porosity and replot the point until it agrees with a previously determined model, or core analysis.

Another technique to analyze log data is the litho-porosity plot of Burke, Schmidt, and Campbel1 (1969). The method makes use of two lithologydependent quantities, $\mathrm{M}$ and $\mathrm{N}$, in which only rock matrix effects remain when one type of porosity is divided by another. The quantity $M$ is obtained by dividing the porosity component of the sonic log by the porosity component of the density log. The quantity $\mathrm{N}$ is derived by dividing the porosity component of the neutron $\log$ by the porosity component of the density log. Since none of the porosities are identical, the remainders in general are representative of the matrix effects seen by the logging instruments:

$$
\begin{aligned}
& M=\frac{\Delta t_{f}-\Delta t}{\rho_{b}-\rho_{f}} X .01 \\
& N=\frac{\Phi_{n f}-\Phi_{n}}{\rho_{b}-\rho_{f}}
\end{aligned}
$$

where $\Delta t_{f}=$ interval transit time of water, in $\mu s / f t$

$\Delta t=$ interval transit time from $10 g$, in $\mu s / f t$

$\rho_{b}=$ bulk density from $\log$, in $\mathrm{g} / \mathrm{cm}^{3}$

$\rho_{\mathrm{f}}=$ density of water, in $\mathrm{g} / \mathrm{cm}^{3}$

$\Phi_{\mathrm{nf}}=$ fluid porosity value from neutron $\log (1.0$, for $100 \%$ water $)$

$\Phi_{\mathrm{n}}=$ porosity from neutron $10 \mathrm{~g}$, a decimal fraction between 0.0 and 1.0

The $M$ term is multiplied by the constant .01 solely to make $M$ values of the same order of magnitude as the $\mathrm{N}$ values, for graphing purposes. When ideal log values for various mineral grains of zero porosity are solved in terms of $M$ and $N$, the matrix end points fall in well-defined regions on the $\mathrm{M}-\mathrm{N}$ plot. 
Table 2 lists the $\mathrm{M}$ and $\mathrm{N}$ yalues for each of the 13 zones from the Randolph core hole. These values are plotted on figure 6 , with the matrix end points for dolomite, limestone, sandstone, and anhydrite. A few zones lie near the dolomite or limestone end points, but most are scattered above and below lines connecting the end points. Zones may fall above the dolomite-limestone line due to so-called secondary porosity effects. Voids in the rock that are somewhat larger than the intergranular pore spaces tend to be bypassed by the sonic $\log$, because the acoustic wave travels around these openings more rapidly than across them. The sonic log, therefore, records too low an interval transit time for the amount of porosity present in the rock; this tends to increase the value of $M$ and shift the points upward. Zones may fall below the dolomite-sandstone line, due to the effects of shale. With ideal rocks and perfect logging instruments, all data points would fall either at the end points on figure 6 or on the lines connecting them. Zone 9 falls on the line between dolomite and limestone, and zones 1 , $5,6,11$, and 12 are near connecting lines. Zones $2,3,4,7$, and 8 all fall considerable distances above the dolomite-limestone line. To determine if these displacements are due to porosity that the sonic tool overlooked, another plot of the 13 zones on a sonic-neutron pair of axes was prepared (figure 7). Zones 2, 3, 4, 7, and 8 all plot near the dolomite line, but figure 5, which has the best mineralogy resolution, indicates zone 2 is mostly limestone, and zones $3,4,7$, and 8 are various mixtures of limestone and dolomite. Evidently the sonic tool is recording an interval transit time that is too short for the porosity actually present in the rock.

Table 2.--Computed values of $\mathrm{M}$ and $\mathrm{N}$ for Randolph core hole

Zone Depth

(ft)

\begin{tabular}{rrrr}
\hline 1 & $634.0-635.5$ & 0.818 & 0.585 \\
2 & $671.5-673.0$ & .853 & .580 \\
3 & $755.5-758.0$ & .814 & .518 \\
4 & $798.5-801.0$ & .812 & .563 \\
5 & $802.0-805.0$ & .780 & .509 \\
6 & $848.5-851.5$ & .780 & .560 \\
7 & $983.5-986.0$ & .817 & .547 \\
8 & $1,004.5-1,010.0$ & .812 & .543 \\
9 & $1,015.0-1,020.0$ & .798 & .544 \\
10 & $1,037.5-1,039.5$ & .765 & .553 \\
11 & $1,055.5-1,057.5$ & .792 & .546 \\
12 & $1,068.5-1,072.0$ & .824 & .566 \\
13 & $1,156.0-1,157.5$ & .774 & .566 \\
\hline
\end{tabular}




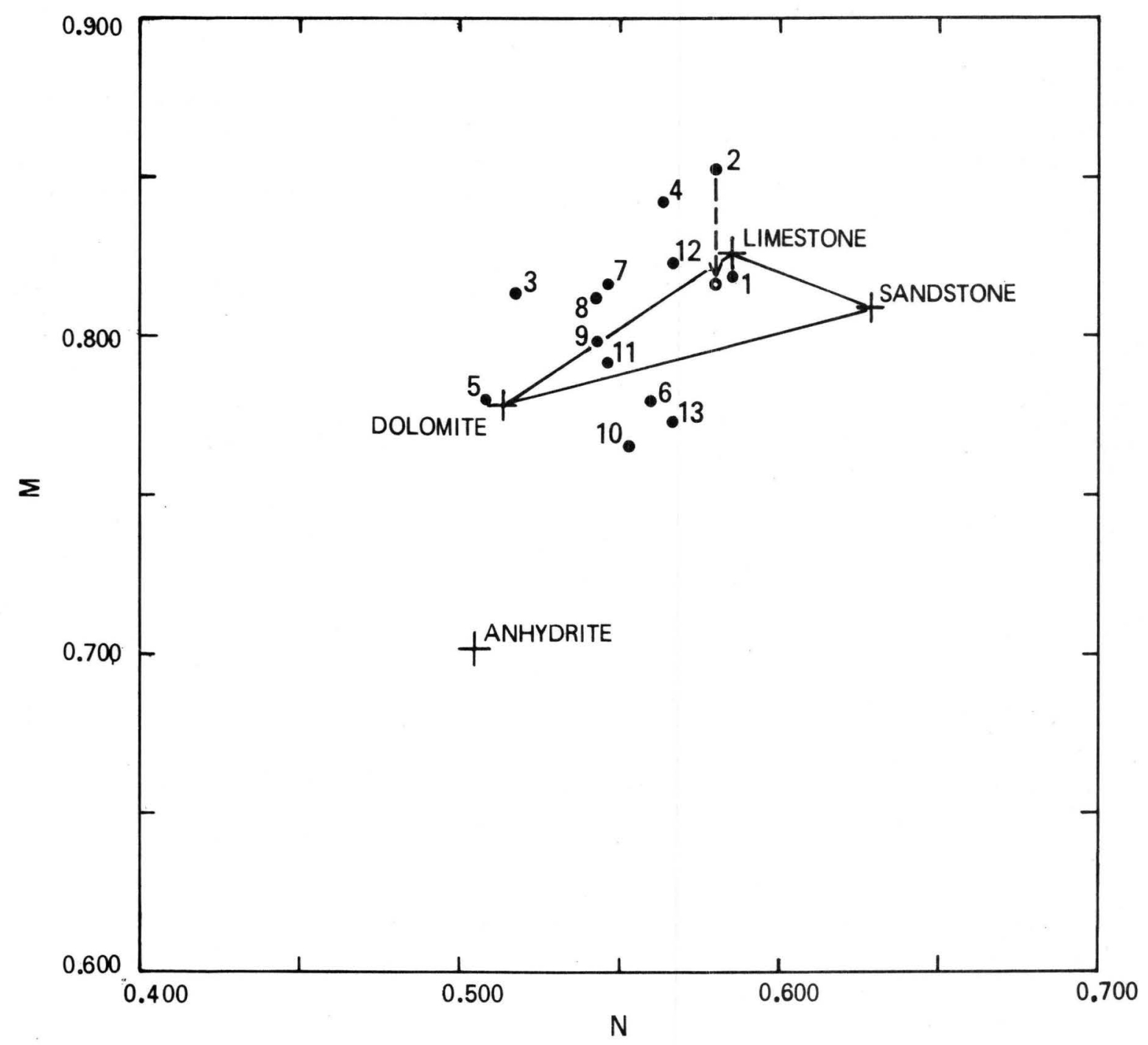

Figure 6.--M-N plot of 13 zones from Randolph core hole. 


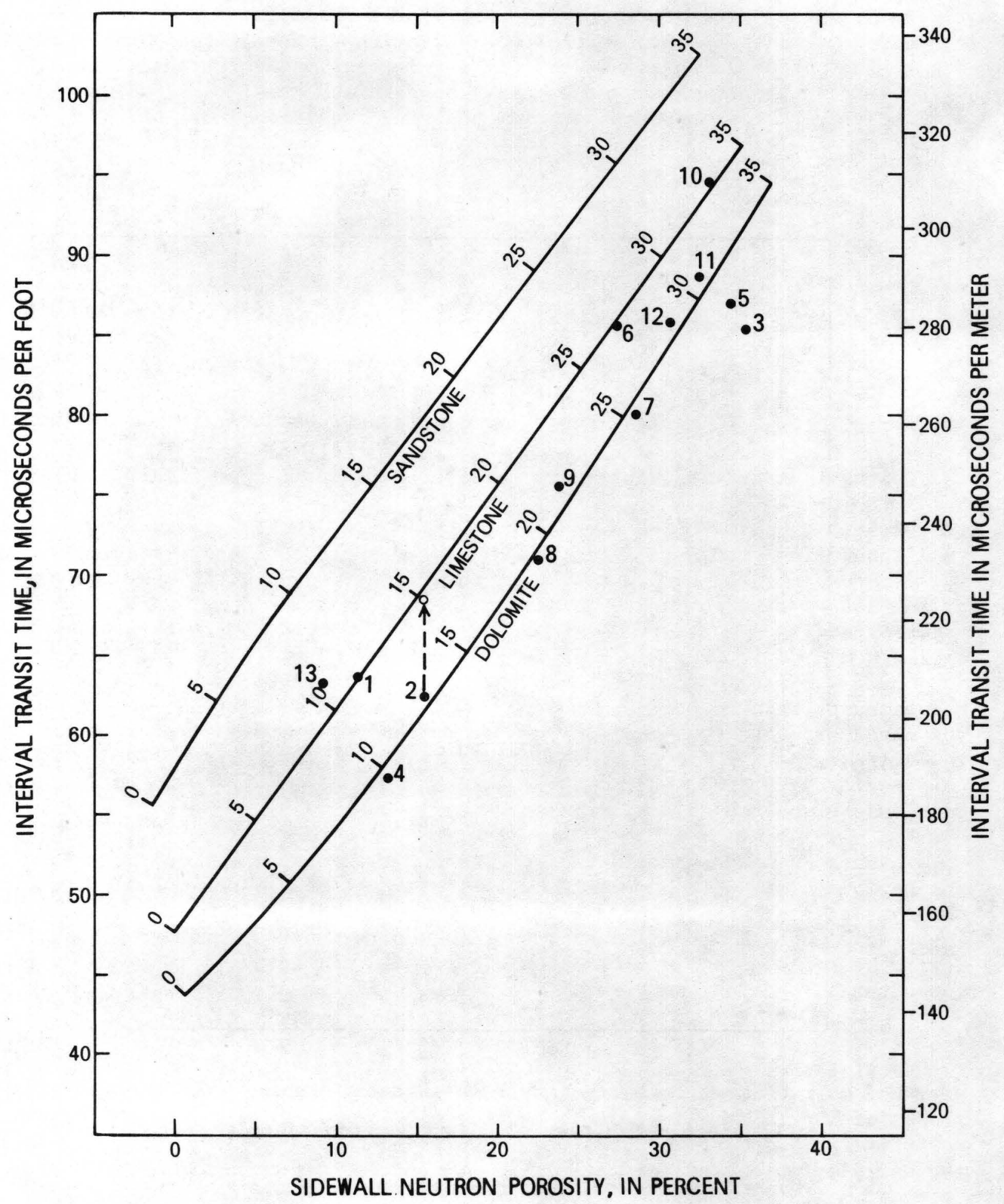

Figure 7.--Sonic-neutron plot of 13 zones from Randolph core hole. 
Zone 2 on figure 5 appears to be about 93 percent limestone and 7 percent dolomite. Using the interpolation method described for zone 9 on figure 5, we can estimate a matrix density of $2.72^{+} \mathrm{g} / \mathrm{cm}^{3}$ and a matrix corrected porosity of 15.1 percent. Entering the interpolated density in figure 13-8 of Schlumberger (1969) gives a matrix interval transit time of $47.2 \mu \mathrm{s} / \mathrm{ft}$. The new values of $\Phi=15.1$ percent and $\Delta$ tma $=47.2 \mu \mathrm{s} / \mathrm{ft}$ can be used to solve for an apparent $\Delta t$ from the sonic equation,

$$
\Delta t=\Phi \Delta t_{f}+(1-\Phi) \Delta t m a
$$

where $\Delta t$ is interval transit time from $\log$ in $\mu \mathrm{s} / \mathrm{ft}$

$\Phi$ is porosity as decimal value

$\Delta t_{f}$ is interval transit time of water (about $189 \mu \mathrm{s} / \mathrm{ft}$ )

$\Delta$ tma is interval transit time of matrix in $\mu \mathrm{s} / \mathrm{ft}$ from figure 13-8,

to obtain a value of about $68.6 \mu \mathrm{s} / \mathrm{ft}$. This value represents what the sonic tool should have recorded if it had "seen" all of the porosity present in the rock. A new $M$ value for this $\Delta t$ will move zone 2 down to the position shown by the dashed line on figure 6. It is apparent that at least part of the shift of zone 2 and others on figures 6 and 7 is due to porosity not recorded by the sonic tool. Whether or not this porosity should be called secondary is a matter of geologic interpretation. In the literature, it is assumed to be secondary solution openings. The dashed line on zone 2 in figure 7 shows the magnitude of the shift required to move the $\Delta t$ value to its new position. the difference in $\Phi$ for $\Delta t$ values of $62.5 \mu \mathrm{s} / \mathrm{ft}$ recorded by the $10 \mathrm{~g}$ and $68.6 \mu \mathrm{s} / \mathrm{ft}$ calculated, is about 4.3-percent porosity, which represents the magnitude of the so-called secondary porosity.

Each zone could be adjusted to obtain a more reasonable plot position on the various cross plot diagnosis by following the above procedure. Computer programs routinely perform this kind of analysis to force the data to fit a lithologic model. If the model is based on core analysis and other factual data, the $10 \mathrm{~g}$ analysis will yield useful data. If the model is wrong or conjectural, the log analysis will also be in error.

Another plotting technique for $10 \mathrm{~g}$ analysis is the pattern recognition method of Pickett (1973). Instead of plotting log data points on a field of presumed matrix lines or end points, the shape of the data cloud and the slopes of the fitted lines are interpreted in terms of rock matrix, fluid resistivity, and water saturation. Saturation usually is not a problem for the hydrologist because he works with 100-percent water-saturated rocks. 
Two commonly used relationships are employed in the method:

$$
\begin{aligned}
F & =\mathrm{R}_{0} / \mathrm{R}_{\mathrm{W}} \\
\text { and } F & =\frac{1}{\Phi^{\mathrm{m}}}
\end{aligned}
$$

where $\mathrm{F}$ is formation resistivity factor

$R_{0}$ is formation resistivity (completely saturated with native water) in ohm-meters

$\mathrm{R}_{\mathrm{W}}$ is formation water resistivity in ohm-meters

$\Phi \quad$ is porosity in decimal value

m is cementation exponent.

Combining the two relationships, results in the equation

$$
R_{0}=R_{w} \Phi^{-m}
$$

but in order to plot on a log-log graph, this equation is expressed as

$$
\log R_{0}=-m \log \Phi+\log R_{w}
$$

This equation means that a $\log -\log$ plot of $R_{O}$ and $\Phi$ will be a line of slope $-m$ for zones of constant water resistivity. Assuming that the type of rock remains the same, other water resistivities will result in a family of curves of the same slope, each one intersecting the 100-percent porosity line at a value equal to $R_{W}$. Thus, the data can be analyzed for changes in $R_{W}$ in the saturated environment, whereas it is usually analyzed for water saturation (Sw) in the petroleum environment. Typically, a deeply focused resistivity log (LL-7, LL-3, or LL-d) and a porosity log (acoustic, density, or neutron) are plotted on the graph paper. Figure 8 is such a plot of resistivity from the deep laterolog (LL-d) and the sidewall neutron porosity $10 \mathrm{~g}$ (SNP) for the 13 zones of the Randolph well. Most of the zones fall in a linear trend, sloping down toward increasing resistivity at lower porosities. Equation (3) indicates that at 100-percent porosity (only water in the logging environment), the $R_{O}$ value equals $R_{W}$. Thus, a line fitted through the data points in figure 8 should intersect the 100-percent porosity line at a value of $R$ equal to the formation water resistivity. The solid line on figure 8 has been fitted by least squares to zones 1-12, and intersects the 100-percent porosity value at $5.3 \mathrm{ohm}$-meters. This value should be representative of the 


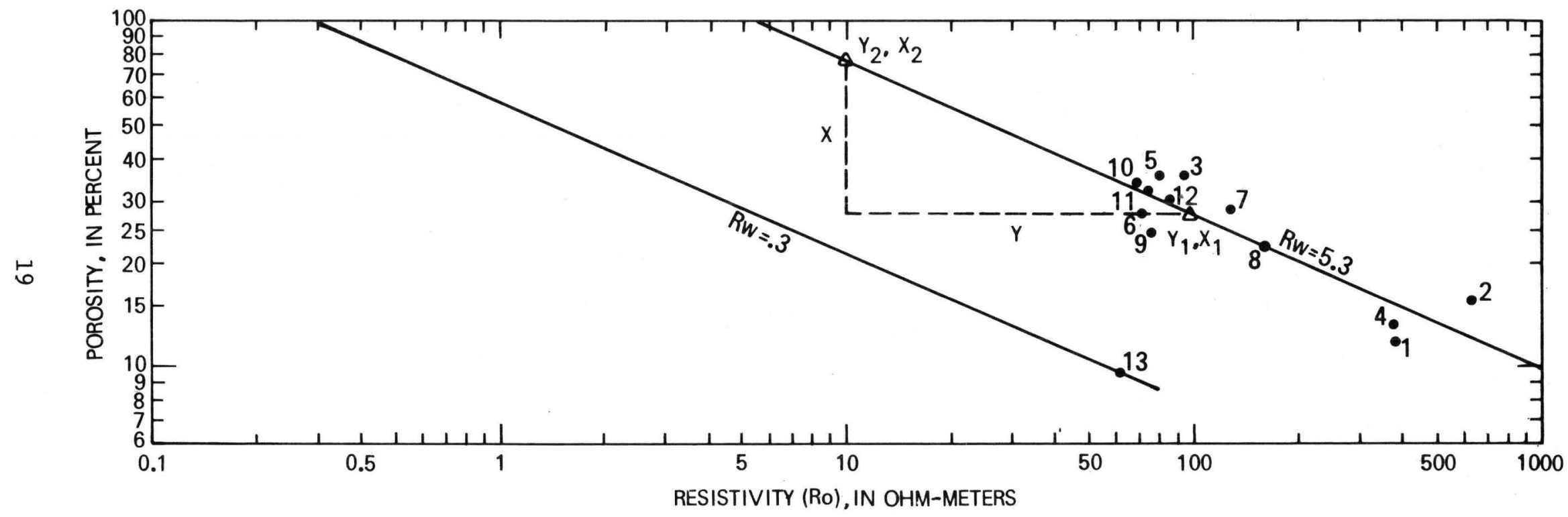

Figure 8.--Porosity-resistivity plot of 13 zones from Randolph core hole. 
average water resistivity for the 12 zones. Zone 13 must have much less resistive water, because a line through it and parallel to that for zones 1-12 intersects the 100-percent porosity value at $0.3 \mathrm{ohm}$-meters. Borehole fluid studies indicate that $\mathrm{R}_{\mathrm{W}}$ ranged up to about 5.4 ohm-meters in the upper part of the hole, and below 1 ohm-meter in the region of zone 13 .

The slope of these lines is defined as

$$
\mathrm{m}=\frac{\mathrm{Y}_{1}-\mathrm{Y}_{2}}{\mathrm{X}_{1}-\mathrm{X}_{2}}
$$

where $\mathrm{Y}_{1}, \mathrm{Y}_{2}$ are the intercepts along the $\mathrm{R}_{0}$ axis, and $\mathrm{X}_{1}, \mathrm{X}_{2}$ are the correponding intercepts along the porosity axis. Since the plot is on logarithmic paper, the logarithm of each value must be taken. For example, the triangle in dashed lines on figure 8 is laid off so that $Y_{1}=100, Y_{2}=10$ (one $\log$ cycle of $R_{o}$ values), and $X_{1}=27.45, X_{2}=75.90$ porosity units read from the graph; thus, the slope

$$
\begin{aligned}
m & =\frac{\log 100-\log 10}{\log 27.45-\log 75.90} \\
m & =\frac{1}{-0.44} \\
& =-2.26 .
\end{aligned}
$$

It is, therefore, possible to estimate the value of $\mathrm{m}$, the cementation exponent in equation (3), and the value of $R_{w}$, from a plot of porosity and resistivity data. In the above example, $m$ was determined to be 2.21 from core measurements.

An advantage of this method over other plotting routines is that the porosity logs need not be calibrated. In fact, according to Pickett (1973, p. 9,10$)$, an empirical calibration of acoustic, density, or neutron log data can be determined by examining the slope of the fitted curves. Using the acoustic $10 \mathrm{~g}$, for example, various trial-and-error values of $\Delta$ tma are subtracted from the $\log$ value of $\Delta t$ until a straight line is fitted to the data. The same technique works for the bulk-density $10 g$ by choosing suitable values of matrix density, pma.

The Sabinal core hole is typical of a well penetrating a carbonate environment that has undergone much solution by ground water. This well lies within the fresh-water zone, which is called locally the Edwards aquifer (Maclay and Sma11, 1976). Figure 9 shows the sonic, three-arm caliper, induction, compensated neutron, and bulk-density logs of the Sabinal core 
hole. The SP, caliper, and gamma ray occur in various combinations in the left track of some of the above-listed logs. Commercial logging services use a pad-type caliper that tends to straddle many of the smaller openings in the rocks. For this reason, the commercial caliper logs make the borehole appear much smoother than is actually the case. The three-arm caliper in figure 9 indicates that there are many thin porous zones that lie in a nearly horizontal plane and reach 10 in diameter. Several large porous zones exceed 14 in. diameter.

Although the commercial logs are borehole-compensated, there is no practical way to adjust the values they record to correct for very rugose hole conditions. For example, nearly all of the high porosities, low bulk densities, and longer interval transit times above $600 \mathrm{ft}$ can be correlated with the hole enlargements displayed by the sensitive caliper log.

The seven zones listed in table 3 were picked for log analysis based mainly on caliper sections that were close to drilling-bit size. It is virtually impossible to find porosities greater than 17.5 percent on the neutron log that are not due to hole enlargements. If these higher-porosity zones are used in the $10 \mathrm{~g}$ analysis, these zones will plot near the dolomite line on figure 10 even though only a little dolomite was found in the core. This happens because too much neutron porosity shifts the data to the right. Hole enlargement affects the sonic and density logs also; thus, they will record sonic transit times that are too long and bulk densities that are too low for the kind of rock penetrated by the borehole.

Table 3.--Geophysical log data from Sabinal core hole

\begin{tabular}{|c|c|c|c|c|c|}
\hline Zone & $\begin{array}{l}\text { Depth } \\
\text { (ft) }\end{array}$ & $\begin{array}{c}\text { Average } \Delta t \\
\mu s / f t \\
(\mu s / m)\end{array}$ & $\begin{array}{c}\text { Average } \\
{ }^{\phi} \mathrm{CNL} \\
\text { percent }\end{array}$ & $\begin{array}{c}\text { Average } \\
\rho_{\mathrm{b}} \\
\mathrm{g} / \mathrm{cm}^{3}\end{array}$ & $\begin{array}{c}\text { Average } \\
\mathrm{R}_{\text {ILD }} \\
\text { ohm-meters }\end{array}$ \\
\hline $\begin{array}{l}1 \\
2 \\
3 \\
4 \\
5 \\
6 \\
7\end{array}$ & $\begin{array}{l}308.5-310.0 \\
448.5-450.0 \\
496.5-498.5 \\
566.0-567.5 \\
606.0-607.5 \\
669.0-671.0 \\
681.0-682.5\end{array}$ & $\begin{array}{l}59.3 \\
52.8 \\
56.8 \\
53.2 \\
66.9 \\
63.4 \\
66.2\end{array}$ & $\begin{array}{r}10.8 \\
6.3 \\
10.7 \\
5.5 \\
17.5 \\
11.5 \\
14.6\end{array}$ & $\begin{array}{l}2.51 \\
2.64 \\
2.53 \\
2.63 \\
2.44 \\
2.60 \\
2.50\end{array}$ & $\begin{array}{l}486.4 \\
348.2 \\
476.8 \\
927.2 \\
580.0 \\
251.8 \\
205.6\end{array}$ \\
\hline
\end{tabular}

The compensated neutron-log response to rock matrix is different from that of the side-wall neutron log, and a slightly different graph is used to plot the data points. Except for zone 6, all zones on figure 10 plot on or near the limestone matrix line. Zone 6 lies below the limestone line, 


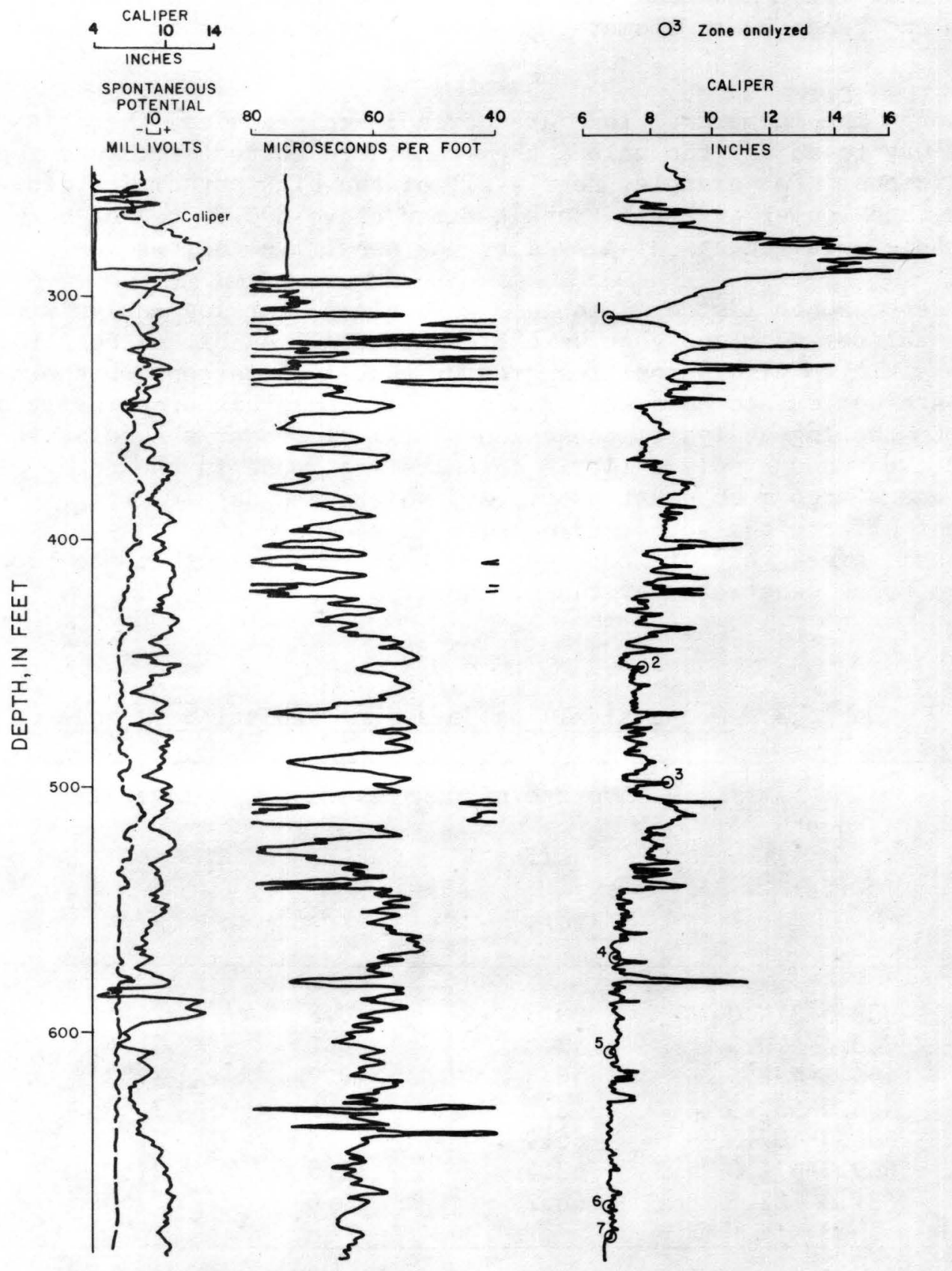

Figure 9.--Geophysical logs of the Sabinal core hole. 


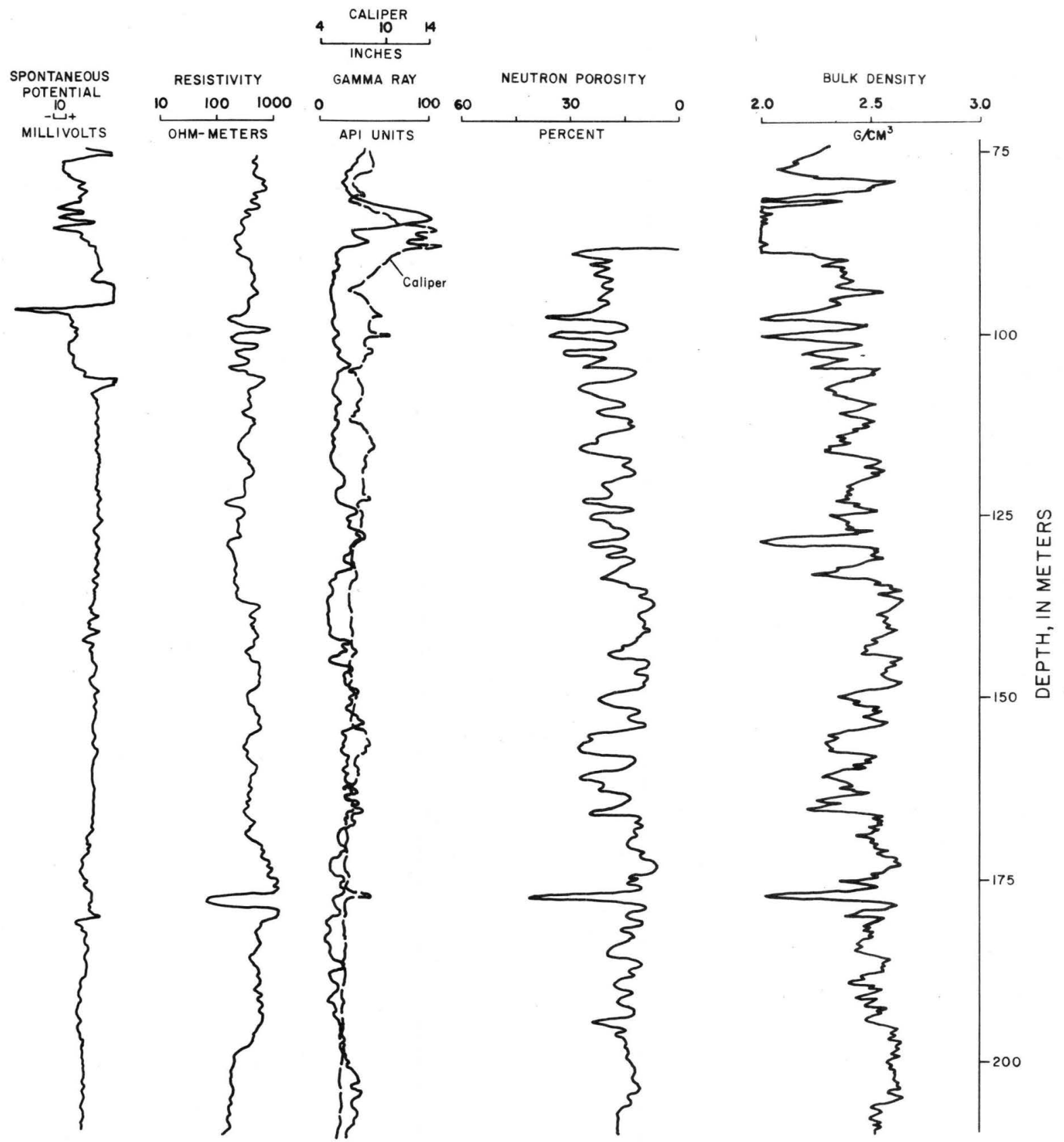

Figure 9.--Continued 


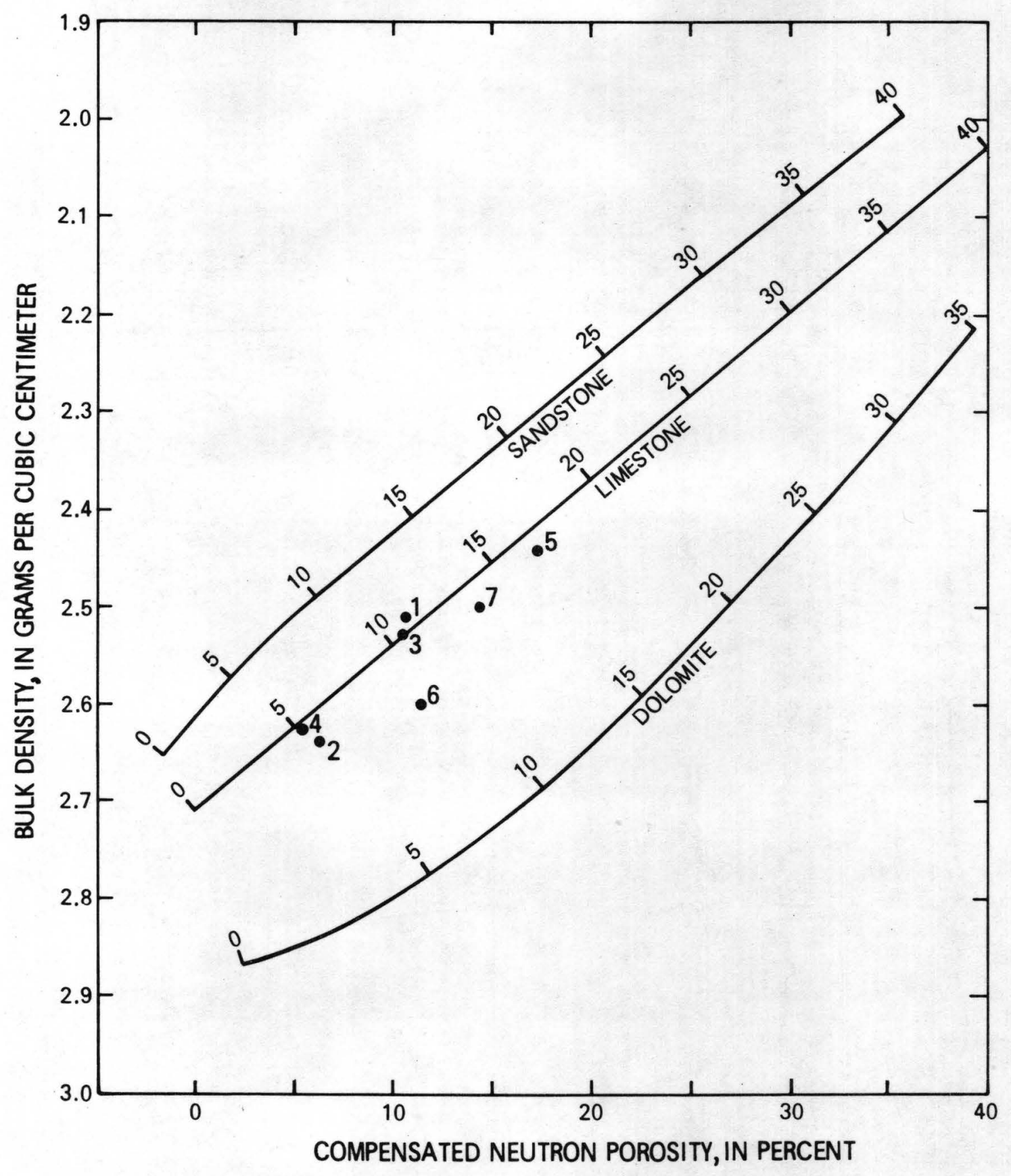

Figure 10.--Neutron-density plot of seven zones from Sabinal core hole. 
probably due to the presence of thin shale beds and shaley limestone in the lower part of the hole. Table 4 lists the computed values of $\mathrm{M}$ and $\mathrm{N}$ for the seven zones in the Sabinal core hole, and these are plotted on figure 11, the M-N diagram. With the exception of zone 6 , all the zones fall near the limestone end point. Zone 6 is displaced down and to the left of the other zones, due to the effects of shaley limestone in this part of the core hole.

Table 4.--Computed values of $\mathrm{M}$ and $\mathrm{N}$ for Sabinal core hole

\begin{tabular}{llrr}
\hline Zone & $\begin{array}{c}\text { Depth } \\
(f t)\end{array}$ & $\mathrm{M}$ & $\mathrm{N}$ \\
\hline & & & 0.591 \\
1 & $308.5-310.0$ & 0.846 & .572 \\
2 & $448.5-450.0$ & .818 & .583 \\
3 & $496.5-498.5$ & .851 & .580 \\
4 & $566.0-567.5$ & .821 & .573 \\
5 & $606.0-607.5$ & .834 & .553 \\
6 & $669.0-671.0$ & .805 & .569 \\
7 & $681.0-682.5$ & & \\
\hline
\end{tabular}

Zones 1, 3, and 5 plot above the limestone end point on figure 11, which may happen because the sonic tool senses only the porosity within the rock matrix and not the larger solutional openings. Figure 12, the sonic-neutron plot of the seven zones, indicates that these points are displaced in the direction of dolomite, even though their position on figure 10 shows them on or close to limestone. These displacements are probably due to unrecorded porosity on the sonic log. Assume zone 3, which falls on the limestone line in figure 10 , is in fact limestone with a matrix interval transit time of $47.5 \mu \mathrm{s} / \mathrm{ft}$ and a porosity of 10.7 percent. Solving (3), the previously used equation for $\Delta t$, gives an interval transit time of $62.6 \mathrm{\mu s} / \mathrm{ft}$. This is the $\Delta t$ that should have been recorded rather than $56.8 \mu \mathrm{s} / \mathrm{ft}$ had the sonic tool "seen" all of the porosity. The difference between these values, $5.8 \Delta t$ units, is sufficient to move zone 3 from its present position on figure 12 back up to the limestone line as shown by the dashed line. The limestone porosity at a $\Delta t$ of $56.8 \mu \mathrm{s} / \mathrm{ft}$ is 6.6 percent, and at a $\Delta t$ of $62.6 \mu \mathrm{s} / \mathrm{ft}$ is 10.7 percent. The difference between these, 4.1 percent, is the amount of secondary porosity left undetected by the sonic log. A new value of $M$ for a $\Delta \mathrm{t}$ of $62.6 \mu \mathrm{s} / \mathrm{ft}$ will shift zone 3 downward on figure 11 , as shown by the dashed line.

Zones 2 and 7 may contain small amounts of dolomite; for that reason, they plot in the dolomite direction on figure 11. 


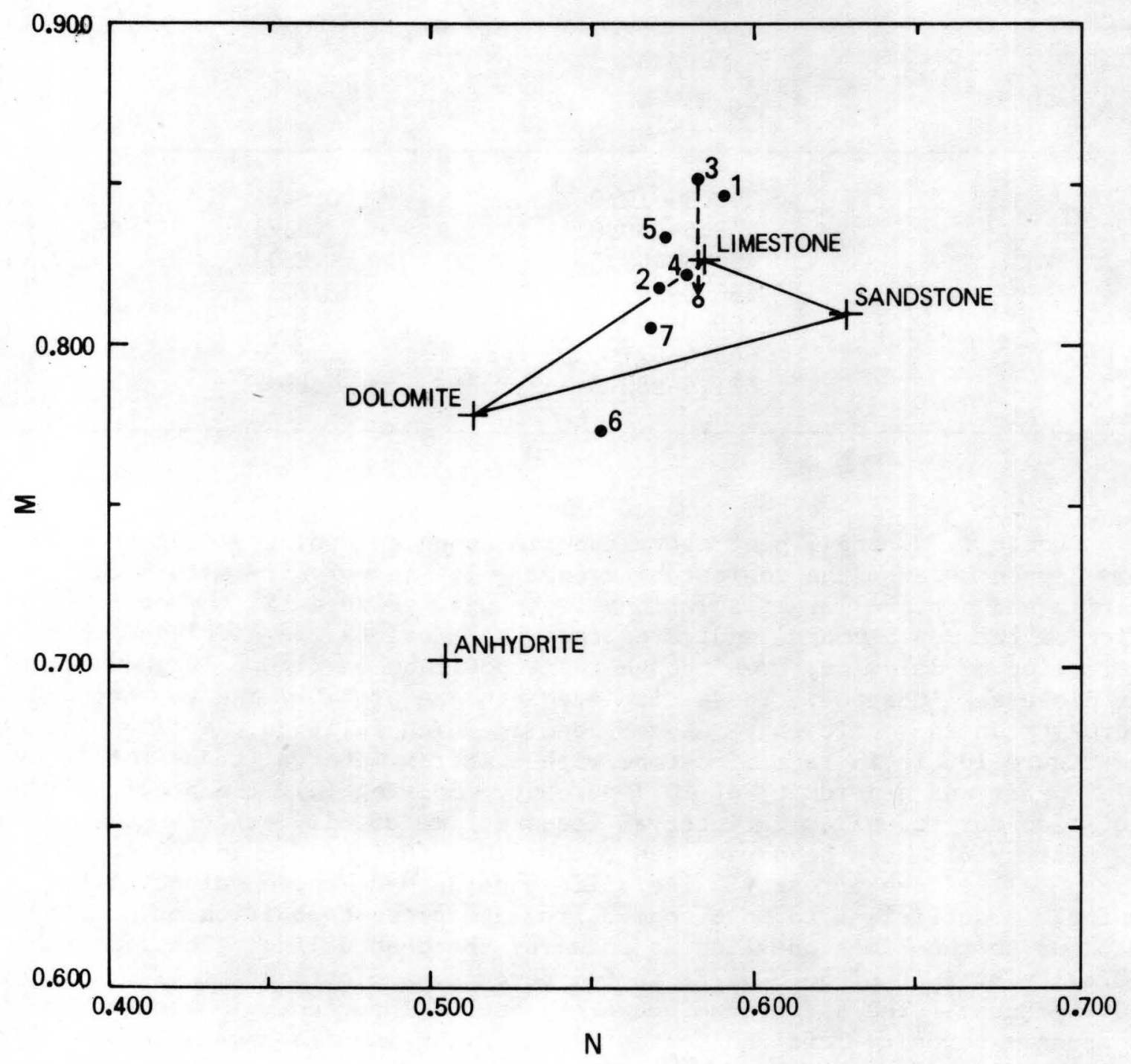

Figure 11.--M-N plot of seven zones from Sabinal core hole. 


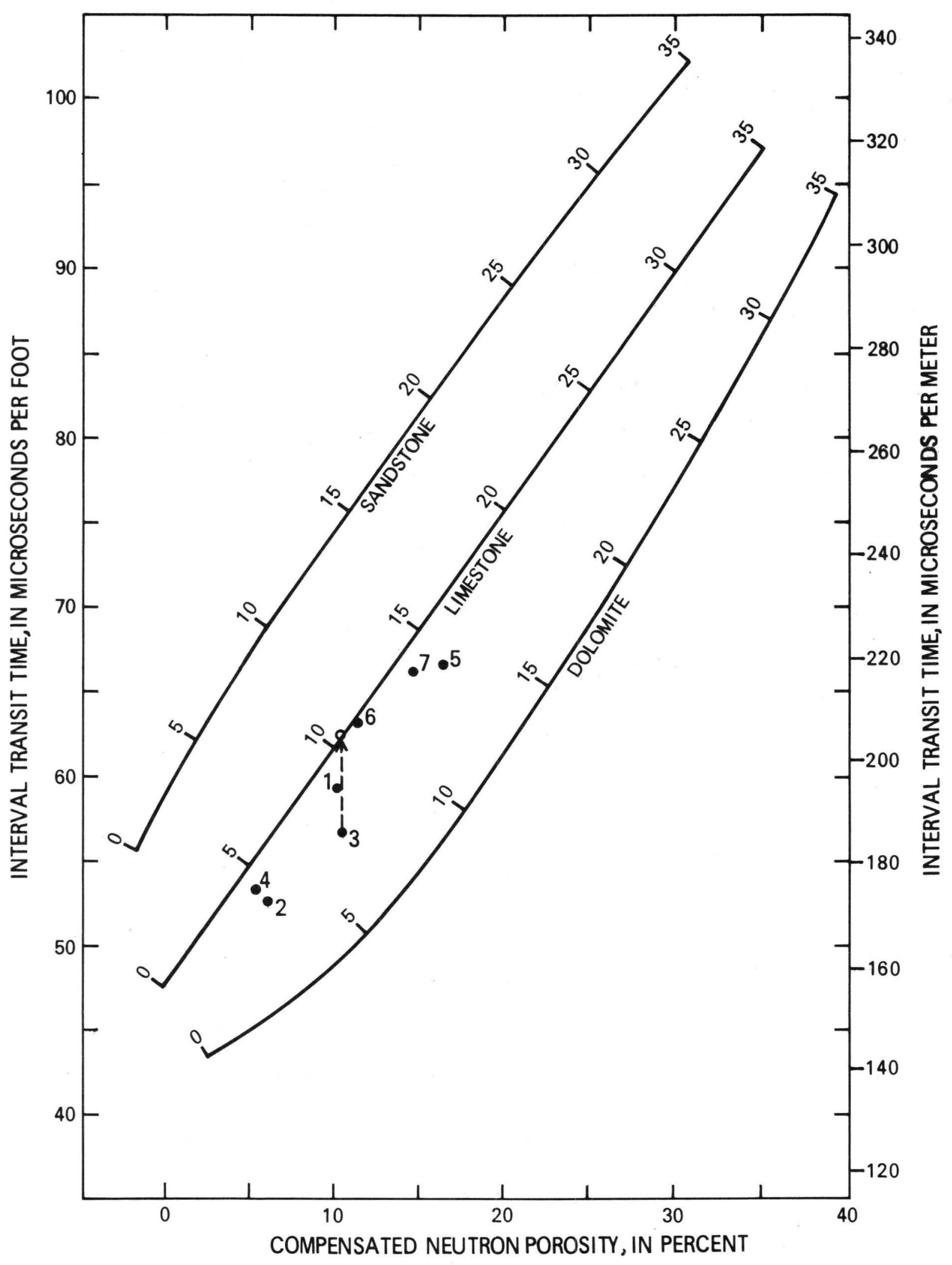

Figure 12.--Sonic-neutron plot of seven zones from Sabinal core hole. 
Attempts to plot induction resistivity and neutron porosity in order to solve for $R_{W}$ proved fruitless. The seven zones scatter to such an extent that a meaningful line could not be fitted to the data. A later electrical survey of the Sabinal core hole indicates that the resistivity of most of the rocks was more than $500 \mathrm{ohm}$-meters, and some sections reached nearly 3,000 ohm-meters. Such high resistivities cannot be recorded with accuracy by the induction tools, which may account for the scatter of the data points and the lack of a we11-defined trend.

\section{SIGNIFICANT RESULTS OF QUANTITATIVE LOG ANALYSIS}

The rocks penetrated by the Randolph and Sabinal core holes characterize a broad, lagoonal carbonate deposition for the former, and a barrier reef deposition for the latter according to Maclay and Small (1976). The rocks penetrated are not representative of all possible carbonates, but the loganalysis techniques and study of the core indicate that the 13 zones picked in the Randolph core hole include type I A, B, D, type II A-D, and type III A-D carbonate rocks as classified by Archie (1952). The seven Sabinal corehole zones include mostly carbonates of classification III A-D. According to Archie, type $I$ is a compact crystalline rock having porosities of 1 to 5 percent. The porosity is not generally effective because the pores are not connected by open-throats, and the permeability is generally less than $1 \mathrm{mD}$ (millidarcy). Type II is a chalky or earthy rock composed of particles less than 0.00197 in. diameter. The particles are less tightly interlocked than those of type I, but the permeabilities of type II rocks are usually less than $1 \mathrm{mD}$. Type III is a granular or sucrosic rock in which the particles are only partially in contact with each other, leaving interconnected pore spaces. Total porosities range from less than 15 percent to about 40 percent. Permeabilities usually are higher than in type I and type II rocks and may range up to $1,000 \mathrm{mD}$ or more.

The sizes of visible pores are divided into four classes in the Archie system. Size A is not visible under a magnification of 10 times $(0.00039$ in. diameter); size B can be seen under a magnification of 10 times $(0.00039-$ 0.0039 in. diameter); and size $C$ is visible to the unaided eye $(0.0039-$ 0.039 in. diameter). Size D includes pores that are greater than 0.039 in. diameter.

We1l-log analysis of these two core holes generates data that might not be so obvious from an examination of core alone or the several well logs by themselves. For example, log analysis indicates that the Randolph core hole penetrates carbonate rocks ranging in composition from all limestone to all dolomite, and with various mixtures of the two. The porosity of the rock ranges from about 9 to 35 percent, and most of the rock with porosities greater than 15 percent is dolomite or dolomitic limestone. The porosity and matrix densities can be estimated from the position of each zone on the neutron-density plot. Shales make up only a very small percentage of the rock in the 13 zones, as evidenced by their positions on the $\mathrm{M}-\mathrm{N}$ plot. Large shale contents would shift points markedly in the southwest direction. The carbonates in many of the zones exhibit significant amounts of secondary porosity judging from their positions on the $\mathrm{M}-\mathrm{N}$ plot and the sonic-neutron 
graph. The approximate magnitude of the secondary porosity can be estimated by calculating a new interval transit time, $\Delta t$, using the interpolated matrix density and matrix corrected porosity from the neutron-density cross plot. The resistivity of the formation water, $R_{\mathrm{W}}$, can be estimated from a log-log plot of formation resistivity, $\mathrm{R}_{\mathrm{O}}$, and porosity. Furthermore, the slope, $\mathrm{m}$, of the line through these points is the cementation exponent, a measure of rock tortuosity.

Many of the same type of calculations are done with the Sabinal well; however, certain precautions must be observed. The Sabinal core hole penetrates carbonate rocks that have experienced much ground-water solution, and large openings are evidenced by deflections on the caliper log. The logging instruments "see" relatively large volumes of water and small volumes of rock in these enlarged sections of the well, and, therefore, record biased data. Using carefully selected zones, the log analyst can tell that the Sabinal well penetrates carbonates, which are dominantly limestone, minor amounts of shale, and perhaps a little dolomite in zones 2 and 7 . Several zones exhibit secondary porosity, which can be determined from their plotted positions on the $\mathrm{M}-\mathrm{N}$ plot and the sonic-neutron graph. Zone 3 appears to have about 4 percent secondary porosity, which was not recorded by the sonic log. Sections of very large secondary porosity, of course, show up on the logs as high porosity, low bulk density, cycle skips on the sonic log, and hole enlargements on the caliper log. Cycle skips are random excursions on the sonic log usually produced by washouts, gas, or high attenuation, and can be seen on the Sabinal sonic $\log$ above $340 \mathrm{ft}(103.6 \mathrm{~m})$. Because the resistivities measured by the induction tool are probably not representative of the actual resistivities, it is not practical to calculate $R_{\mathrm{w}}$ and a value of $\mathrm{m}$, the cementation exponent.

Other lithologies that are associated with some carbonates are halite, gypsum, and anhydrite. None of these were found in the two core holes analyzed; however, their log response is very distinctive and they can generally be recognized by the log analyst. Halite has an interval transit time of $67 \mu \mathrm{s} / \mathrm{ft}$, a neutron porosity of 4 percent or less, and a matrix density of about $2.03 \mathrm{~g} / \mathrm{cm}^{3}$. Furthermore, halite exhibits a very high resistivity on the deeply penetrating logs. Gypsum has a $\Delta t$ of $52.0 \mu \mathrm{s} / \mathrm{ft}$, an apparent neutron porosity of 49 percent (due to water of crystallization), a matrix density of $2.35 \mathrm{~g} / \mathrm{cm}^{3}$, and a high resistivity on deeply penetrating logs. Anhydrite has an interval transit time of $50 \mu \mathrm{s} / \mathrm{ft}$, a matrix density of $2.98 \mathrm{~g} / \mathrm{cm}^{3}$ (one of the highest in sedimentary rocks), and a neutron porosity near zero. The resistivity of anhydrite is also very high.

\section{SUMMARY}

Acoustic, density, and neutron logs with supporting data from the caliper, gamma, and resistivity logs can be used to calculate many rock and fluid parameters in the carbonate environment. Much useful data can be determined by carefully selecting a few zones in each well for detailed analysis. The log analysis, which can be accomplished by hand plotting and a few simple 
calculations, will yield quantitative data enabling the hydrologist to evaluate carbonate reservoirs, and, furthermore, help him design computer methods for well-log analysis. It is usually more productive to initially analyze a few zones in each well by hand methods to gain an understanding of the rock and fluid characteristics, than to run a computer-program package. Because programs are of a standard format and tend to force fit the data to a specific reservoir model, it is better to determine the model first by core studies and $\log$ analysis. A good programmer can then discard bad data points previously detected, so the hydrologist is not required to explain anomalies caused by computations based on poor information.

\section{REFERENCES}

Archie, G. E., 1952, Classification of carbonate reservoir rocks and petrogeophysical considerations: American Association of Petroleum Geologists Bulletin, v. 36 , no. 2, p. 278-297.

Burke, J. A., Schmidt, A. W., and Campbe11, R. L., 1969, The litho-porosity cross plot: Log Analyst, v. 10, no. 3, p. 25-43.

Chilingar, G. V., Mannor, R. W., and Rieke, H. H., 1972, Oil and gas production from carbonate rocks: New York, American Elsevier Publishing Co., Inc., $397 \mathrm{p}$.

Jeffries, F., 1969, Simplified theory of multiple log analysis: Canadian Well Logging Society Journal, v. 2, no. 1, p. 5-17.

MacCary, L. M., 1971, Resistivity and neutron logging in silurian dolomite of northwest Ohio: U.S. Geological Survey Professional Paper 750-D, p. D19-D197.

Maclay, R. W., and Small, T. A., 1976, Progress report on geology of the Edwards aquifer, San Antonio area, Texas, and preliminary interpretation of borehole geophysical and laboratory data on carbonate rocks: U.S. Geological Survey Open-file Report 76-627, 65 p.

Pickett, G. R., 1973, Pattern recognition as a means of formation evaluation: Society of Professional Well Log Analysts, 14th Annual Logging Symposium, Lafayette, La., May 1973 Transactions, p. A1-A21.

Raymer, L. L., and Biggs, W. P., 1963, Matrix characteristics defined by porosity computations: Society of Professional Well Log Analysts, 4th Annual Logging Symposium, Oklahoma City, Okla., May 1963 Transactions, p. X1-X21.

Schlumberger Well Surveying Corp., 1958, Introduction to Schlumberger well logging (Schlumberger Document no. 8): Houston, Tex., $176 \mathrm{p}$.

Schlumberger Limited, 1969, Log interpretation--principles (Schlumberger Document): New York, 110 p. 